DOI 10.37882/2500-3682.2020.12.32

\title{
ПСИХОСОЦИАЛЬНАЯ РАБОТА С ЛИЧНОСТЬЮ, НАХОДЯЩЕЙСЯ В КРИЗИСНОЙ СИТУАЦИИ
}

\section{PSYCHOSOCIAL WORK WITH A PERSON IN A CRISIS SITUATION}

\section{E. Rubanova}

Summary: During the review of the main technologies of psychosocial work with a person in a crisis situation, the author considered such concepts as crisis, its place in human life and the process of its development, situations that can lead to a crisis. Overcoming the crisis, the individual goes through a process of experience, which is an internal work to fill his life with a new meaning, restore his state of mind. The emotional sphere changes greatly, and a person begins to experience Ioneliness, depression, or a destructive feeling as the dominant feeling. The author considers the technologies and components of psychosocial work with a person in a crisis situation.

Keywords: crisis, crisis situation, emotional sphere, traumatic crisis, experience.

\author{
Рубанова Евгения Юрьевна \\ к.nсх.н., Тихоокеанский государственный \\ университет, г. Хабаровск, \\ blizru@bk.ru
}

Аннотация: В ходе рассмотрения основных технологий психосоциальной работы с личностью, находящейся в кризисной ситуации автором были рассмотрены такие понятия как кризис, его место в жизни человека и процессе его развития, ситуации, которые могут привести к кризису. Преодолевая кризис, личность проходит через процесс переживаний, представляющую из себя внутреннюю работу по наполнению новым смыслом своей жизни, восстановлению душевного состояния. Сильно меняется эмоциональная сфера, человек начинает испытывать в качестве доминирующего чувства одиночества, депрессию или деструктивное чувство. Автором рассмотрены технологии и компоненты психосоциальной работы с личностью, находящейся в кризисной ситуации.

Ключевые слова: кризис, кризисная ситуация, эмоциональная сфера, травматический кризис, переживание.
K ризис представляет собой нарушение психического, душевного и эмоционального состояния человека, внутреннего равновесия или саморегуляции человека, повлекшие за собой воздействия внешней среды. В развитии личности кризис имеет большое значение, так как дальнейший путь развития человека в посткризисный период, будь то конструктивный путь или деструктивный сложит его дальнейшую жизнь. Кризис не существует сам по себе, он является последствием чувственного восприятия различных природных, социальных, экономических ситуаций или воздействий, который влекут за собой переживания или действия, которые человек не может разрешить самостоятельно. Любой человек на протяжении своей жизни сталкивался с различными кризисами и переживаниями, связанные с ним, например, возрастные кризисы. В теории ведущими к кризису называются жизненные события, если они «создают потенциальную или актуальную угрозу удовлетворению основных потребностей...» [1] и ставят перед человеком такую проблему «от которой он не может уйти и которую не может разрешить при помощи имеющихся в его опыте способов адаптации» [1]. В итоге мы имеем, что кризис - критический момент, пункт, решающий дальнейшую жизнь, кризис жизни. Согласно В. В. Козлова «кризис - это всегда момент выбора из нескольких возможных альтернатив, момент выбора регрессивного или прогрессивного решения в дальнейшем развитии» [2].
Ситуации, которые могут привести к тому или иному кризисному состоянию бывают:

- Возрастные кризисы, возникающие при переходе на следующую возрастную ступень;

- Травматический кризис как ответ на стрессовые события (война, потеря близких, болезнь, травма и т.п.) выражается через кризисные реакции: посттравматическое стрессовое расстройство - затяжная или отставная реакция переживания последующая после травматического стресса; острая реакция на некое событие в жизни, несущее угрозу жизни и здоровью человека (катастрофа, война, изнасилование); шоковая травма - болезненная реакция, отсроченная во времени на шоковую травму, может проявиться через несколько лет, может быть выражено через психосоматическое заболевание или необъективное поведение. Травматический кризис в любом случае нарушает базовое чувство безопасности человека.

- Экзистенциальные кризисы - когда личная трансформация переходит на новый этап развития.

Кризис в своем развитии проходит через 4 последовательные стадии [4]:

1. На первой стадии развития кризиса происходит рост напряжения и стимуляция привычных способов решениях проблем;

2. Привычные способы разрешения проблем становятся безрезультативными, напряжение все боль- 
ше увеличивается;

3. Напряжение продолжает расти, на помощь приходит мобилизация внутренних и внешних источников сил;

4. Если все предпринятые усилия оказываются напрасными, далее следует стадия повышения тревоги и депрессия, сопровождающаяся чувством безнадежности и беспомощности, приводящая в конечном итоге к дезорганизации личности.

Преодолевая кризис, личность проходит через процесс переживаний, представляющую из себя внутреннюю работу по наполнению новым смыслом своей жизни, восстановлению душевного состояния [4]. Различают такие виды переживаний как:

- Реалистическое переживание. Человек спокойно и трезво воспринимает случившееся, приспосабливается к новой реалии, понимая, что возврат прошлого не возможен.

- Ценностное переживание - человек признает само наличие кризисной ситуации, но не признает ее пассивное принятие, дальнейшая жизнь строится с учетом понесенной потери.

- Гедонистическое переживание - человек не принимает факт случившихся перемен, игнорирует и отрицает их, в дальнейшем он формирует иллюзию благополучия и поддерживает ее.

- Творческое переживание чаще всего возникает у волевых сложившихся людей, в кризисной ситуации такой человек будет сознательно искать выход.

В кризисной ситуации происходит воздействие на разные аспекты жизни человека:

- Воздействие на саму личность приводит к появлению чувства одиночества, стыда, низкой самооценки, повышенной раздражительности; возникает апатия, тревога, депрессия, агрессия и пр.

- Воздействие в целом на поведение приводит к таким негативным последствиям как: нарушение сна, алкоголизм, наркомания, тремор, нарушение речи, эмоциональные срывы и пр.

- Воздействие на здоровье приводит к развитию многочисленных психосоматических заболеваний: бронхиальная астма, болезни сердца, обмороки, диабет, бессонница и пр.

- Воздействие на физиологию приводит к повышению глюкозы в крови, артериального давления, приступам жара и озноба, усиленному потоотделению, ощущение кома в горле и пр.

- Когнитивные эффекты - психологические симптомы, такие как невозможность принять решения или сосредоточиться, заторможенность, повышенное внимание к критике.
Эмоциональная сфера сильно меняется в кризисной ситуации, человек начинает испытывать в качестве доминирующего чувства одиночества (чувство ненужности, тупика, безнадежности), депрессию (апатия, равнодушие, тоска, усталость, безразличие) или деструктивное чувство (обида, злость, досада, ненависть, зависть, упрямство).

Обратимся к непосредственному рассмотрению психосоциальной работы с личностью, находящейся в кризисной ситуации. Структура технологии психосоциальной работы имеет два подразделения - это общие (функциональные) и частные. К первым относятся методы и методики, имеющие всеобщий характер и могут быть применимы к большинству категорий лиц, в том числе к лицам, находящимся в кризисной ситуации. Система психосоциальной работы включает в себя такие важные компоненты как: коррекция, экспертиза, терапия, диагностика, посредничество, адаптация, профилактика, страхование, моделирование, опека, реабилитация, консультирование, благотворительная деятельность. В отличие от общих частные технологии работы направлены на помощь конкретным категориям людей и социальным слоям: безработным гражданам, лицам с девиантным поведением, инвалидам, пожилым людям, подросткам, людям без определенного места жительства, малообеспеченным и т.д.

Психосоциальная работа с личностью, находящейся в кризисной ситуации, включает в себя следующие технологии:

- Диагностика - социологический опрос, интервью, мониторинг, биографический метод, экспертная оценка и прогноз, и т.д.

- Профилактика - социальная терапия, группа социальной поддержки, превентивный метод и т.д.

- Контроль - социальная опека, социальное обслуживание, социальный надзор и т.д.

- Реабилитация - психодрама, трудотерапия, социальная опека и т.д.

Во всех перечисленных технологиях психосоциальной помощи можно наблюдать три основных компонента:

- Инициирование потенциала самопомощи в кризисной ситуации;

- Оказание помощи посредством поддержки, консультирования, патронажа, реабилитации и других психосоциальных услуг;

- Формирование и реализация грамотной социально-экономической политики с целью создания системы поддержки граждан и обеспечения психосоциальной среды жизнедеятельности человека пригодной для жизни. 


\section{ЛИТЕРАТУРА}

1. Осухова Н.Г. Психологическая помощь в трудных и экстремальных ситуациях: учебное пособие. - М., 2008. - С. 28

2. Козлов В.В. Работа с кризисной личностью. Методическое пособие. - М., 2007.- С. 10

3. Тарабрина Н.В. Практикум по психологии посттравматического стресса. - СПб., 2001.

4. Василюк Ф.Е. Психология переживания - М.: Изд-во Московского ун-та, 1984. - 200 с.

5. Фирсов М.В., Шапиро Б.Ю. Психология социальной работы: Учеб. пособие. - М., 2002. - 192 с.

\section{() Рубанова Евгения Юрьевна (blizru@bk.ru).}

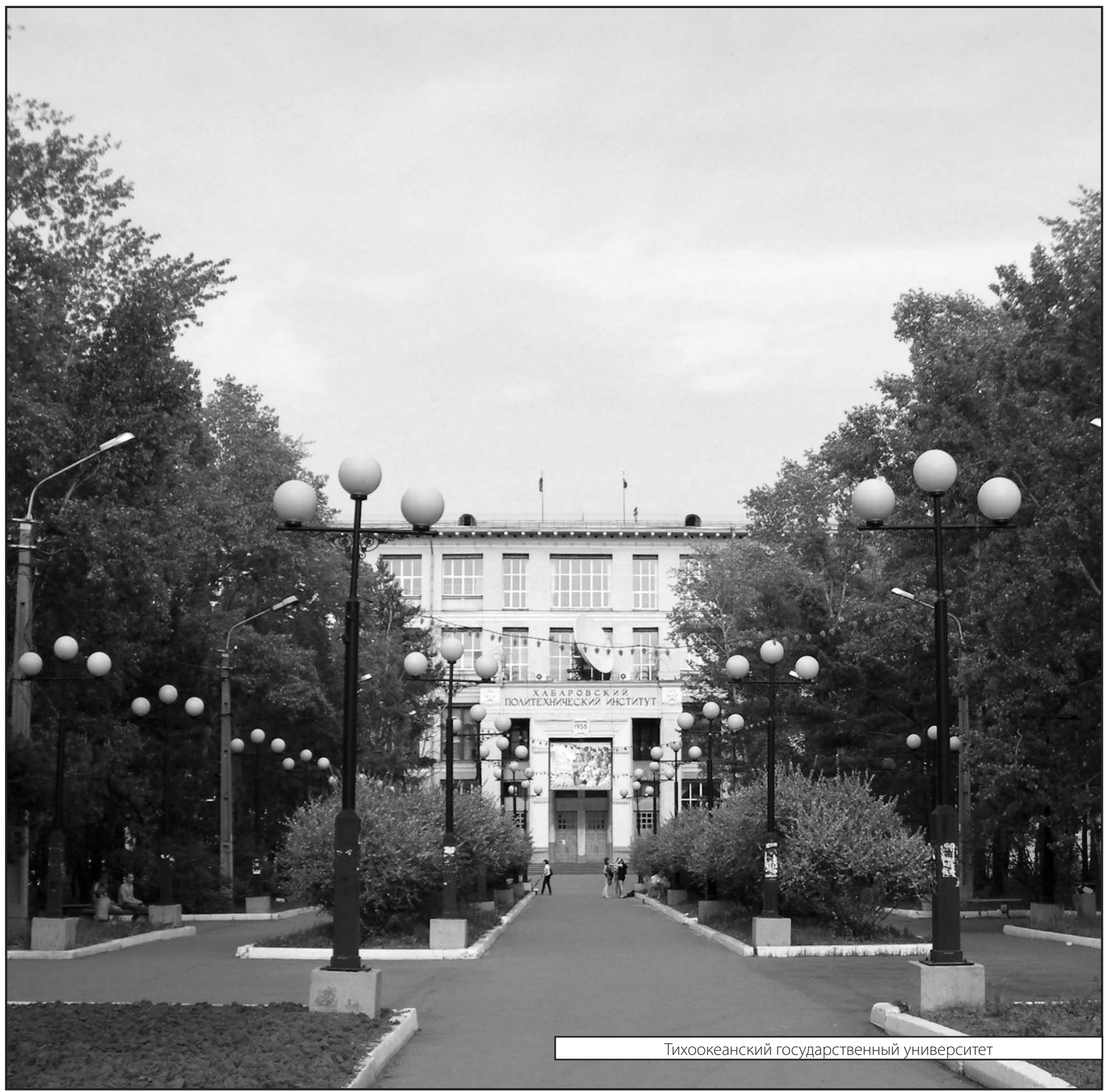

